\title{
A Deep Intronic HADH Splicing Mutation (c.636+471G>T) in a Congenital Hyperinsulinemic Hypoglycemia Case: Long Term Clinical Course
}

\author{
Emine Çamtosun1, Sarah E. Flanagan2, Sian Ellard2, Zeynep Şıklar1, Khalid Hussain3,4, \\ Pınar Kocaay1, Merih Berberoğlu1 \\ ${ }^{1}$ Ankara University Faculty of Medicine, Department of Pediatric Endocrinology, Ankara, Turkey \\ 2 Exeter University Faculty of Medicine, Institute of Biomedical and Clinical Science, Exeter, UK \\ 3UCL Institute of Child Health, Genetics and Epigenetics in Health and Disease Genetics and Genomic Medicine \\ Programme, London, UK \\ ${ }^{4}$ Great Ormond Street Hospital for Children, Clinic of Pediatric Endocrinology, London, UK
}

\begin{abstract}
Unlike other congenital fatty acid oxidation defects, short-chain L-3hydroxyacyl-CoA (SCHAD, HADH) deficiency is characterised by hypoglycemia with hyperinsulinism in the neonatal or infancy periods. The long-term and detailed clinical progression of the disease is largely unknown with almost 40 patients reported and only a few patients described clinically. We present clinical and laboratory findings together with the long-term clinical course of a case with a deep intronic $H A D H$ splicing mutation (c.636+471G $>$ T) causing neonatal-onset hyperinsulinemic hypoglycemia with mild progression.
\end{abstract}

Key words: $H A D H$ mutation, hyperinsulinemic hypoglycemia, children

Conflict of interest: None declared

Received: 19.02 .2015

Accepted: 07.04 .2015

\section{Introduction}

Persistent congenital hyperinsulinemic hypoglycemia $(\mathrm{CHH})$ can be caused by mutations in the ABCC8/KCNJ11, GLUD1, HADH, GCK, HNF4A, HNF1A, SLC16A1 and UCP2 genes $(1,2)$. $A B C C 8 / K C N J 11$ mutations are most common (33-66\%) and GLUD1 mutations are the second commonest cause of $\mathrm{CHH}$, identified in approximately $5 \%$ of the cases. Mutations in other known genes (including $H A D H$ ) together account for less than $4 \%$ of $\mathrm{CHH}$ (1).

Loss of function mutations in the HADH (HADHSC, SCHAD) gene, causing short-chain L-3-hydroxyacyl-CoA (SCHAD) deficiency, were first reported to cause persistent $\mathrm{CHH}$ in 2001 (3). SCHAD catalyses the penultimate step in the mitochondrial fatty acid oxidation pathway, the NAD+dependent conversion of L-3-hydroxyacyl-CoA to 3-ketoacylCoA (1). The main clinical feature of this metabolic disease is hypoketotic hypoglycemia with hyperinsulinism which is different from other inherited defects of fatty acid $\beta$-oxidation that can present with symptoms such as hepatomegaly, myopathy and cardiomyopathy. HADH mutations are recessively inherited and most of the reported cases are from consanguineous families. So far, approximately 40 patients with $\mathrm{CHH}$ resulting from a mutation in the HADH gene have been reported (Table 1) $(3,4,5,6,7,8,9,10,11,12$, $13,14,15)$. The mechanism behind unregulated insulin secretion in SCHAD deficiency is currently not understood but may involve changes in protein-protein interactions with glutamate dehydrogenase (GDH) $(16,17)$. 
The clinical presentation is mainly neonatal- or early infancy-onset $\mathrm{HH}$ and patients are diazoxide-responsive. It has also been shown that these patients have severe protein (especially leucine) sensitivity $(10,16,17)$. Metabolic profiling in some, but not all, affected individuals reveals a raised plasma hydroxybutyrylcarnitine and urinary medium-chain dicarboxylic, 3-hydroxydicarboxylic metabolites and 3-hydroxyglutarate levels.

Here we present the long-term follow-up of a case with a deep intronic HADH splicing mutation (c.636+471G>T) causing hyperinsulinemic hypoglycemia and review the reported cases so far.

\section{Case Report}

A 13.9-year-old girl was admitted to our hospital with complaints of headache and weakness. She had a convulsion attack with hypoglycemia one day before admission. Her medical history revealed that she had been diagnosed with persistent $\mathrm{CHH}$ at the age of 30 days following admission to a health center for generalised convulsion. She was born at term with a weight of $4000 \mathrm{~g}$. Following the diagnosis of $\mathrm{CHH}$, she was commenced on $10 \mathrm{mg} / \mathrm{kg} /$ day of diazoxide and remained on that dose for five years.

\begin{tabular}{|c|c|}
\hline Mutations & References \\
\hline p.P258L (c.773C>T) & Clayton et al (3) \\
\hline p.? (c.547-3_549del) & Molven et al (8) $(n=2)$ \\
\hline p.? (c.710-2A>G) & Hussain et al (9) \\
\hline p.M188V (c.562A>G) & Kapoor et al (10) \\
\hline \multirow{3}{*}{ p.R236X (c.706C>T) } & DiCandia et al (13) \\
\hline & Flanagan et al $(5)(n=6)$ \\
\hline & Sogno Valin S et al (12) \\
\hline p.S196fs (c.587del) & Martins et al (4) $(n=3)$ \\
\hline p.? (c. $261+1 G>A)$ & Martins et al (4) \\
\hline Not available & Kapoor et al (6) $(n=3)$ \\
\hline p.K136E $(406 \mathrm{~A}>\mathrm{G})$ & Flanagan et al (5) \\
\hline p.0163X (c.487C>T) & Flanagan et al (5) \\
\hline \multirow{2}{*}{$\begin{array}{l}\text { p.K95fs (c.283_293delinsT)/ } \\
\text { p.? (c.709+39C>G) }\end{array}$} & Flanagan et al (5) \\
\hline & Snider et al $(7)(n=2)$ \\
\hline p.? (c.1-3440_132+1943del) & Flanagan et al $(5)(n=2)$ \\
\hline p.G34A (c.100 G>C) & Snider et al (7) \\
\hline p.T189fs (c.565del) & Popa Fl et al (14) \\
\hline p.? $($ c. $636+471 G>T)$ & Flanagan et al (11) $(n=8)$ \\
\hline
\end{tabular}

At the age of 2 years, the patient was lost to followup for 5 years. Then, she presented at seven years of age with generalized convulsion with a hypoglycemic attack due to interrupted intake of medicine. After restarting diazoxide therapy $(10 \mathrm{mg} / \mathrm{kg} /$ day) with regular intake, the girl did not have any hypoglycemic attacks but developed hypertrichosis.

At the age of 12.5 years, the patient was re-evaluated in another medical center. During hypoglycemia, her insulin level was detected to be very high $(78.8 \mu \mathrm{lU} / \mathrm{mL})$. Urinary amino acids and blood spot tandem mass were normal; there were no reducing substances in the urine. The results of a prolonged oral glucose tolerance test were normal. The diazoxide dose was tapered to $2.5 \mathrm{mg} / \mathrm{kg} /$ day slowly without episodes of hypoglycaemia. Drug cessation was tried but because of repeated hypoglycemic attacks diazoxide was started again at a dose of $2.5 \mathrm{mg} / \mathrm{kg} / \mathrm{day}$. When the girl was first admitted to our clinic after a hypoglycemic convulsion, she had complaints of headache and weakness, but physical examination was normal; height $153 \mathrm{~cm}(-0.93 \mathrm{SD})$ and weight $47 \mathrm{~kg}$, body mass index (BMI) was $20.08 \mathrm{~kg} / \mathrm{m}^{2}$. She was hospitalized for further evaluation. A fasting test was performed, but hypoglycemia was not detected during a 12-hour fast. While she was taking diazoxide $2 \mathrm{mg} / \mathrm{kg} / \mathrm{day}$, a non-ketotic hypoglycemic attack (blood glucose: $46 \mathrm{mg} / \mathrm{dL}$ ) was detected with a very high insulin level (46.8 $\mu \mathrm{lU} / \mathrm{mL})$. During this episode, blood gas sampling, blood ammonia, cortisol and adrenocorticotropic hormone were all within the normal range.

Cranial MRI and an electroencephalogram did not reveal any pathology. Normoglycemia was maintained with diazoxide $3 \mathrm{mg} / \mathrm{kg} /$ day. Genetic studies by Sanger sequencing did not reveal any mutations in the $A B C C 8, K C N J 11$ or GLUD1 genes, however, sequencing of $H A D H$ identified a previously reported homozygous splicing mutation within intron 5 (c.636+471G>T) (Figure 1) (10). The parents who are not known to be consanguineous were both heterozygous for the mutation. The patient is currently 20 years of age and in good health.

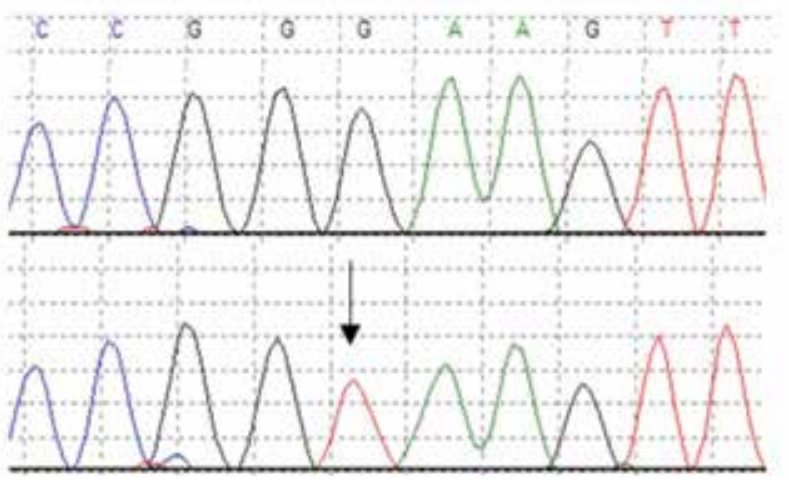

Figure 1. Electropherogram showing the homozygous c. $636+471 \mathrm{G}>\mathrm{T}$ cryptic splicing mutation in intron 5 of the $\mathrm{HADH}$ gene (lower panel). A sequence trace for a control (upper panel) 
Mental status and neurological examination were normal at her last follow-up visit. She was reported to have maintained her academic performance at the higher education institution she was attending. Her blood glucose levels continued to be at normal levels with the low dose $(2-3 \mathrm{mg} / \mathrm{kg} /$ day) of diazoxide she has been receiving. She has reached her final height which is within normal ranges and has a BMI of $24.8 \mathrm{~kg} / \mathrm{m}^{2}$.

Informed consent was given by the patient.

\section{Discussion}

Recessive mutations in the $H A D H$ gene were first described by Clayton et al (3) in a four-month-old infant with hypoketotic hypoglycemia, inappropriately elevated insulin levels and elevated blood spot hydroxybutyrylcarnitine concentration. Since then, another 36 patients have been reported with $H A D H$ mutations $(4,5,6,7,8,9,10,11,12,13,14)$. The clinical presentation of $\mathrm{CHH}$ due to $\mathrm{HADH}$ mutations is heterogeneous with some patients presenting with severe neonatal hypoglycemia and others - with mild infancy-onset hypoglycemia. Our case was born at term with a weight of $4000 \mathrm{~g}$ (1.63 SD) and presented with neonatal hypoglycemic seizure at the age of 30 days. Birth weight of patients with $H A D H$ gene mutation were usually reported as normal from $2730 \mathrm{~g}$ to $4350 \mathrm{~g}(3,4,5,6,7,8,9,10,11$, $12,13,14,15)$. Early admitted patients usually had hypoglycemic seizure as our case $(3,4,5,8,9,10,13,14,15)$. Martins et al (4) reported four new cases and reviewed seven reported cases with $\mathrm{HH}$ due to $\mathrm{HADH}$ deficiency. They found that patients became symptomatic in early life (ranging from 1.5 hours to 8 months) and presented with hypoglycemic convulsions, lethargy and hypotonia. Although their symptoms had begun in infancy, three of the four new cases were diagnosed late and presented with mental retardation, microcephaly. Flanagan et al (5) reported 11 cases with a median age of 7 weeks (1 day-26 weeks) at $\mathrm{HH}$ diagnosis and a median birth weight of $3.6 \mathrm{~kg}(2.8-4.35 \mathrm{~kg})$ at 40 weeks gestation When Kapoor et al (6) studied the clinical and molecular characterisation of 300 patients with $\mathrm{CHH}$, they identified three patients who had $H A D H$ mutations and were diazoxide-responsive. Mean birth weight was $-1.08 \mathrm{SD}$ and mean age at presentation was 125 days in these patients (6). Snider et al (7) investigated genotype and phenotype correlations in 417 children with $\mathrm{CH}$ and reported two diazoxide-responsive patients with $\mathrm{HADH}$ gene mutations. Clinical information was not provided for these patients. Flanagan et al (11) identified eight new diazoxideresponsive $\mathrm{CHH}$ patients with a deep intronic splicing mutation in the $H A D H$ gene by next-generation sequencing.

All cases reported in the literature are diazoxide-responsive with a range in dose used from to $2-15 \mathrm{mg} / \mathrm{kg} /$ day (median $7-8 \mathrm{mg} / \mathrm{kg} / \mathrm{day})(4,5)$. Comparable with other patients reported in the literature, our case was diazoxide-responsive with 10 $\mathrm{mg} / \mathrm{kg} /$ day at the beginning and the maintenance dose at older ages was $2.5-3 \mathrm{mg} / \mathrm{kg} /$ day. To identify and treat $\mathrm{HH}$ earlier is crucial for preventing persistent brain damage. Even for diazoxide-responsive patients, if not treated properly, the outcome can be dramatic like motor mental retardation, cortical blindness, microcephaly, etc. Due to the early diagnosis and proper treatment, our patient's prognosis was very good.

The metabolic profile is heterogeneous in patients with HADH mutations. The first three reported patients had detectable urinary 3-hydroxyglutarate and raised plasma 3-hydroxybutyrylcarnitine levels; subsequently reported cases however did not have abnormal urine organic acids or acylcarnitines (5). We could not analyse the urine organic acid profile of our patient.

Kapoor et al (10) reported a patient with $\mathrm{CHH}$ due to a $H A D H$ gene mutation, who responded to diazoxide but continued to have episodes of hypoglycemia even on diazoxide especially when taking a meal rich in protein. The authors described protein sensitivity in this and two other cases (10). A study by Heslegrave et al (17) further supported this finding and showed that GDH and $H A D H$ have a direct protein-protein interaction which is lost in patients with $\mathrm{HADH}$ gene mutations causing leucine-induced $\mathrm{HH}$. A protein-load test has not been undertaken in our patient, but after a protein-rich meal, blood glucose level was detected as $62 \mathrm{mg} / \mathrm{dL}$. There is almost no information about clinical findings of these patients with the same mutation. Only limited clinical findings of two siblings with the same mutation was published as a short report. Both has been admitted to hospital at 40 days of age with hypoglycemia-related seizures. Birth weights were normal in these patients and they were successfully treated with diazoxide. There is no additional follow-up information (15).

Although consanguinity was not reported in our family, most cases in the literature are known to be consanguineous. As the disease is recessively inherited, sequencing of $H A D H$ is recommended in all patients with diazoxide-responsive $\mathrm{CH}$, following exclusion of mutations in $A B C C 8 / K C N J 11$ genes $(1,5)$, who originate from known consanguineous pedigrees, isolated populations or countries where inbreeding is frequent.

So far, reported mutations in the $H A D H$ gene include missense, nonsense, frameshift and splicing mutations, some small deletions and a deep intronic splicing mutation $(3,6,10)$. The mutation identified in our patient was a deep intronic splicing mutation which was first detected by targeted nextgeneration sequencing (11). This mutation has been shown to introduce a cryptic splice donor site which results in pseudoexon activation and a premature termination codon and was also a founder mutation in the Turkish population (11).

In the long-term follow-up period, our patient showed mild $\mathrm{CHH}$. The prognosis was good with low-dose diazoxide treatment. The findings in our patient demonstrate that the recognition of hyperinsulinism as a cause of hypoglycemia in early life and early treatment can prevent neurological deficits especially in diazoxide-responsive forms of $\mathrm{CHH}$ like $\mathrm{HADH}$ deficiency. 


\section{Acknowledgements}

The genetic studies were funded by the Medical Research Council (Grant Number 98144). SF has a Sir Henry Dale Fellowship jointly funded by the Wellcome Trust and the Royal Society (Grant Number 105636/Z/14/Z).

\section{References}

1. Arya VB, Mohammed Z, Blankenstein $O$, De Lonlay $P$, Hussain K. Hyperinsulinaemic hypoglycaemia. Horm Metab Res 2014;46:157-170. Epub 2014 Feb 20

2. Mohamed Z, Arya VB, Hussain K. Hyperinsulinaemic hypoglycaemia:genetic mechanisms, diagnosis and management. J Clin Res Pediatr Endocrinol 2012;4:169-181. Epub 2012 Oct 2

3. Clayton PT, Eaton $S$, Aynsley-Green A, Edginton M, Hussain K, Krywawych S, Datta V, Malingre HE, Berger $R$, van den Berg IE. Hyperinsulinism in short-chain L-3-hydroxyacyl-CoA dehydrogenase deficiency reveals the importance of betaoxidation in insulin secretion. J Clin Invest 2001;108:457465.

4. Martins E, Cardoso ML, Rodrigues E, Barbot C, Ramos A, Bennett MJ, Teles EL, Vilarinho L. Short-chain 3-hydroxyacylCoA dehydrogenase deficiency: the clinical relevance of an early diagnosis and report of four new cases. J Inherit Metab Dis 2011;34:835-342. Epub 2011 Feb 24

5. Flanagan SE, Patch AM, Locke JM, Akcay T, Simsek E, Alaei M, Yekta Z, Desai M, Kapoor RR, Hussain K, Ellard S. Genomewide homozygosity analysis reveals $\mathrm{HADH}$ mutations as a common cause of diazoxide-responsive hyperinsulinemichypoglycemia in consanguineous pedigrees. J Clin Endocrinol Metab 2011;96:498-502. Epub 2011 Jan 20

6. Kapoor RR, Flanagan SE, Arya VB, Shield JP, Ellard S, Hussain K. Clinical and molecular characterisation of 300 patients with congenital hyperinsulinism. Eur $\mathrm{J}$ Endocrinol 201315;168:557-564. Print 2013 Apr

7. Snider KE, Becker S, Boyajian L, Shyng SL, MacMullen C, Hughes N, Ganapathy K, Bhatti T, Stanley CA, Ganguly A. Genotype and phenotype correlations in 417 children with congenital hyperinsulinism. J Clin Endocrinol Metab 2013;98:355-363. Epub 2012 Dec 28

8. Molven A, Matre GE, Duran M, Wanders RJ, Rishaug U, Njølstad PR, Jellum E, Søvik O. Familial hyperinsulinemic hypoglycemia caused by a defect in the SCHAD enzyme of mitochondrial fatty acid oxidation. Diabetes 2004;53:221227.

9. Hussain K, Clayton PT, Krywawych S, Chatziandreou I, Mills P, Ginbey DW, Geboers AJ, Berger R, van den Berg IE, Eaton S. Hyperinsulinism of infancy associated with a novel splice site mutation in the SCHAD gene. J Pediatr 2005;146:706-708.
10. Kapoor RR, James C, Flanagan SE, Ellard S, Eaton S, Hussain K. 3-Hydroxyacyl-coenzyme A dehydrogenase deficiency and hyperinsulinemic hypoglycemia: characterization of a novel mutation and severe dietary protein sensitivity. J Clin Endocrinol Metab 2009;94:2221-2225. Epub 2009 May 5

11. Flanagan SE, Xie W, Caswell R, Damhuis A, Vianey-Saban C, Akcay T, Darendeliler F, Bas F, Guven A, Siklar Z, Ocal G,Berberoglu M, Murphy N, O'Sullivan M, Green A, Clayton PE, Banerjee I, Clayton PT, Hussain K, Weedon MN, Ellard $S$. Next-generation sequencing reveals deep intronic cryptic ABCC8 and HADH splicing founder mutations causing hyperinsulinism by pseudoexon activation. Am J Hum Genet 2013;92:131-136. Epub 2012 Dec 27

12. Sogno Valin P, Proverbio MC, Diceglie C, Gessi A, di Candia S, Mariani B, Zamproni I, Mangano E, Asselta R, Battaglia C,Caruso-Nicoletti M, Mora S, Salvatoni A. Genetic analysis of Italian patients with congenital hyperinsulinism of infancy. Horm Res Paediatr 2013;79:236-242. Epub 2013 May 1

13. Di Candia S, Gessi A, Pepe G, Sogno Valin P, Mangano E, Chiumello G, Gianolli L, Proverbio MC, Mora S. Identification of a diffuse form of hyperinsulinemic hypoglycemia by 18-fluoro-L-3,4 dihydroxyphenylalanine positron emission tomography/CT in a patient carrying a novel mutation of the HADH gene. Eur J Endocrinol 2009;160:1019-1023. Epub 2009 Mar 24

14. Popa Fl, Perlini $S$, Teofoli F, Degani D, Funghini $S$, La Marca G, Rinaldo P, Vincenzi M, Antoniazzi F, Boner A, Camilot M. 3-hydroxyacyl-coenzyme a dehydrogenasedeficiency: identification of a new mutation causing hyperinsulinemic hypoketotic hypoglycemia, altered organic acids and acylcarnitines concentrations. JIMD Rep 2012;2:71-77. Epub 2011 Sep 6

15. Ozsu E, Mutlu GY, Cizmecioğlu FM, Hatun S. HADH Mutation is a Rare Cause of Hyperinsulinaemic Hypoglycaemia. J Clin Res Pediatr Endocrinol 2015;7(Suppl 1):-22.

16. Li C, Chen P, Palladino A, Narayan S, Russell LK, Sayed S, Xiong G, Chen J, Stokes D, Butt YM, Jones PM, Collins HW, Cohen NA, Cohen AS, Nissim I, Smith TJ, Strauss AW, Matschinsky FM, Bennett MJ, Stanley CA. Mechanism of hyperinsulinism in short-chain 3-hydroxyacyl-coa dehydrogenase deficiency involves activation of glutamate dehydrogenase. J Biol Chem 2010;285:31806-31818. Epub 2010 Jul 29

17. Heslegrave AJ, Kapoor RR, Eaton S, Chadefaux B, Akcay T, Simsek E, Flanagan SE, Ellard S, Hussain K. Leucine-sensitive hyperinsulinaemic hypoglycaemia in patients with loss of function mutations in 3-Hydroxyacyl-CoA Dehydrogenase. Orphanet J Rare Dis 2012;7:25. 